\title{
Kajian Geokimia Molekular : Studi KasusKematangan Minyak Bumi Duri Riau, Cekungan Sumatera Tengah
}

\author{
Emrizal Mahidin Tamboesai \\ Jurusan Kimia FMIPA,Universitas Riau, Pekanbaru, Indonesia \\ Email: emrizaltamboesai@gmail.com
}

\begin{abstract}
Abstrak
Untuk mengetahui tingkat kematangan minyak bumi yang diproduksi sumur tua (Sumur X, Y dan $\mathrm{Z})$ dengan sumur baru (W) yang mempunyai kesamaan sifat fisik di WKP Chevron diperlukan pendekatan dengan resolusi tinggi. Studi geokimia molekular digunakan pada kajian kematangan minyak bumi ini. Sidik jari minyak bumi dari analisis GC-MS telah menunjukkan hubungan genetik yang posistif diantara sample teranalisis. Akan tetapi minyak bumi dari sumur baru W menunjukkan hubungan kematangan yang lebih dekat dengan sumur minyak $\mathrm{Z}$ dibanding sumur tua lain (X dan Y).
\end{abstract}

Kata kunci : Kematangan minyak bumi, geokimia minyak bumi, GC-MS

\begin{abstract}
To understand the maturity between the old oil well ( $\mathrm{X}, \mathrm{Y}$ and $\mathrm{Z}$ ) production having the same physical properties in WKP Chevron and a new well ( W). The maturity studies were conducted using Petroleum Geochemistry. Fingerprint of crude oils from GC-MS Analysis show that the maturity correlation among them are positive. However the new oil well $\mathrm{W}$ had a higher positive correlation to the well $\mathrm{Z}$ compared to the old well $\mathrm{X}$ and $\mathrm{Y}$.
\end{abstract}

Keywords : Biomarker, petroleum geochemistry, GC-MS

\section{PENDAHULUAN}

Sejak tahun 1950 ladang minyak bumi Duri yang terletak di cekungan Sumatera Tengah telah terbukti merupakan salah satu cekungan penghasil hidrokarbon yang produktif di Indonesia. Hidrokarbon diproduksi dari 60 lapangan minyak bumi dari cekungan ini, hingga tahun 1996 telah diproduksi 10 milyar barrel (Katz dan Dawston 1997). Semakin sulitnya pencarian cadangan hidrokarbon di cekungan Sumatera Tengah pada tahun belakangan ini, sehingga diperlukan suatu strategi eksplorasi hidrokarbon dengan tingkat keberhasilan yang tinggi.Salah satu upaya yang penting untuk peningkatan efisiensi dan produksi minyak bumi adalah dengan melakukan studi geokimia molekular yang merupakan biomarker minyak bumi dari beberapa sumur produksi guna membantu memecahkan problem kontinuitas disuatu reservoar (Kaufman et al. 1990).

Biomarker merupakan senyawa komplek fosil molekular biologis, yang berasal dari suatu organisme makhluk hidup (Seifert and Moldowan 1981; Tissot dan Welte 1984; Peters dan Moldowan 1993; Hunt 1996), yang telah mengalami proses perubahan gugus fungsi, pemutusan ikatan dan perubahan stereokimia, namun masih menyimpan secara utuh kerangka atom karbon sehingga dapat ditelusuri asal usulnya. Oleh karena itu, biomarker merupakan indikator yang penting untuk mengenal material organik minyak bumi, kondisi perubahan geologi, kimia dan fisika terhadap organisme akibat perubahan yang signifikan oleh panas selama proses diagnesis, katagenesis serta derajat biodegradasinya. 
Penelitian ini bertujuan untuk melakukan kajian biomarker untuk menunjukkan tingkat kematangan minyak bumi Sumur W yang baru ditemukan terhadap minyak bumi sebelumnya dari beberapa sumur minyak bumi dalam satu lapangan produksi di cekungan Sumatera Tengah. Kajian geokimia molekular ini akan dapat menunjukkan tingkat kematanganminyak bumi Duri yang baru ditemukan (W) dan juga dapat menunjukkan dengan minyak bumi dari sumur produksi yang mana minyak bumi dari sumur baru tersebut memiliki korelasi kematangan yang paling dekat. Penelitian ini dilakukan dengan mengidentifikasi senyawa biomarker di dalam minyak bumi dari masing-masing sampel teranalisis, menentukan parameter geokimia molekular yang terdeteksi di dalam minyak bumi untuk selanjutnya digunakan untuk mengelompokkan minyak bumi berdasarkan tingkat kematangannya. Identifikasi senyawa biomarker dilakukan berdasarkan data yang diperoleh dari analisis kromatografi gasspektrometri massa (GC-MS).

\section{METODE PENELITIAN}

\section{Alat dan Bahan}

Bubuk silicalite kering, n-Heksana, dikloro metana, metanol, Bak Pasir kuarsa, Pemanas listrik, Kolom silicalite, GCMS Hewlett Packard (HP) 6890 yang dilengkapi dengan kolom kapiler fused silica Ultra-1, panjang kolom $=50 \mathrm{~m}$, tebal fasa diam $=0.33$ $\mu \mathrm{m}$.

\section{Fraksinasi Minyak Bumi}

Fraksi saturat, aromat dan polar didapat dengan cara fraksinasi minyak bumi. Secara lebih rinci metode yang digunakan sebagai berikut; dibuat kolom yang padat dari silika berukuran partikel 100 mesh, diperlukan empat gram silika untuk setiap percobaan.nHeksana dituangkan pada beaker yang berisi silika dan aduk sampai rata, dan selanjutnya dituang ke kolom sambil digetarkan, sehingga didapat kolom yang padat. Teknik ini menggunakan kolom berdiameter $1 \mathrm{~cm}$, tinggi kolom $20 \mathrm{~cm}$. Lebih kurang $75 \mathrm{mg}$ (50-100 $\mathrm{mg}$ ) minyak ditimbang dalam vial, dengan perlahan lahan minyak diteteskan pada kolom yang telah disiapkan. Berturut-turut dituangkan

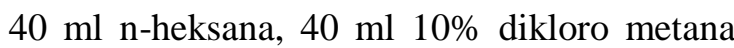
(DCM) dalam n-heksana, dan terakhir campurkan $20 \mathrm{ml}$ dikloro metana (DCM) dan $20 \mathrm{ml}$ metanol sehingga didapat fraksi saturat, aromat dan polar. Masing-masing fraksi dihilangkan pelarutnya dengan memanaskan dalam bak pasir kuarsa pada pemanas listrik. Larutan dipindahkan ke vial $2 \mathrm{ml}$, dikeringkan dengan pemanas listrik sehingga diperoleh berat yang tetap untuk masing-masing fraksi, kemudian ditimbang. Percobaan ini dilakukan untuk masing-masing sampel minyak bumi.

\section{Isolasi Alkana}

Untuk mengisolasi alkana bercabang dan siklik, maka disediakan bubuk silicalite kering $(0.5 \mathrm{~g})$ dimasukkan dan dipadatkan dalam sebuah pipet Pasteur yang didasarnya berisi katun bersih, kolom dibilas dengan $n$ heksana sebelum digunakan. Fraksi saturat dengan berat antara 2-15 mg dalam n-heksana dituangkan dalam kolom, 5 menit kemudian dielusi dengan n-heksana sebanyak empat kali volume silicalite, eluen ditampung dalam vial, pelarutnya diuapkan pelan-pelan, residu silicalite berisi $\mathrm{n}$-heksana yang ditampung mengandung alkana bercabang dan siklik.

\section{Analisis GC-MS Minyak Bumi}

Analisis GC-MS sampel minyak bumi dengan menggunakan instrument Hewlett Packard (HP) 6890 yang dilengkapi dengan kolom kapiler fused silica Ultra-1, panjang kolom $=50 \mathrm{~m}$, tebal fasa diam $=0.33 \mu \mathrm{m}$. Gas Hidrogen digunakan sebagai gas pengemban dengan kecepatan $0.8 \mathrm{ml} /$ menit. Sampel diinjeksikan menggunakan mode on colum injector, dengan temperatur inlet $250{ }^{\circ} \mathrm{C}$, sedangkan pendeteksian digunakan detektor FID yang suhunya dipertahankan pada $325^{\circ} \mathrm{C}$. Temperatur awal dari oven adalah $30{ }^{\circ} \mathrm{C}$ dipertahankan selama 4 menit, lalu suhu 
dinaikkan dengan bertahap, yakni dengan kenaikan $3{ }^{\circ} \mathrm{C} /$ menit hingga suhu $40{ }^{\circ} \mathrm{C}$, kemudian dinaikan $5^{\circ} \mathrm{C} /$ menit hingga tercapai $200^{\circ} \mathrm{C}$. Dengan demikian diperlukan waktu sekitar 70 menit untuk satu kali injeksi sampel.Untuk penentuan sidik jari whole oil diperlukan analisis hidrokarbon dalam kisaran C2-C45. Untuk penentuan puncak alkana siklik maupun asiklik, biomarker $\mathrm{Pr}, \mathrm{Ph}$, dilakukan dengan cara membandingkan waktu retensi dari data yang telah terpublikasikan (Alexander et al.1992; Hunt 1996).

Analisis GC-MS dari fraksi saturat bercabang dan saturat siklik dilakukan dengan menggunakan GC kapiler seri HP 6890 yang dilengkapi dengan MSD (Mass Selective Detector) sistem seri HP 5973 - sistem data komputer (HP Chemstation). GC diperlengkapi dengan $50 \times 0.20 \mathrm{~mm}$ i.d Ulytra1 kolom kapiler fused silica.

Dalam penelitian ini parameter geokimia yang diperoleh dari pengukuran kromatogram GC-MS ditabulasikan.Semua parameter geokimia yang diukur didapat dengan menghitung luas puncak yang sesuai dari kromatogramnya.Ladang minyak Duri yang terletak di cekungan Sumatera Tengah adalah salah satu daerah penghasil minyak terpenting di Indonesia. Cekungan ini tersusun dari sediment Tersier (Koning et al.1984), terletak diantara Bukit Barisan dengan sebelah barat daya sampai keselatan dibatasi oleh patahan sesar naik dari batuan Pra Tersier sepanjang kaki Bukit Barisan dan dibatasi oleh Selat Malaka dari Utara sampai ke Timur. Luas cekungan ini diperkirakan sekitar 120.000 $\mathrm{km}^{2}$.Sampel minyak bumi dari empat sumur produksi Minas Riau telah digunakan untuk keperluan studi ini.Pemilihan sampel minyak dari tiga sumur produksi ( $\mathrm{P}, \mathrm{Q}$ dan $\mathrm{R})$ terdahulu dan Sumur $\mathrm{T}$ yang baru ditemukan tahun 2001.

\section{HASIL DAN PEMBAHASAN}

\section{Sterana}

Fraksi hidrokarbon saturat rantai lurus, bercabang dan siklik sampel yang berasal dari sumur minyak $\mathrm{W}$ dan tiga sumur produksi yang terpilih dianalisis dengan metoda GCMS. Identifikasi puncak-puncak kromotogram massa yang penting diperhatikan ialah berturut-turut puncak nomer 3-12 sterena yang ada pada gambar 1 berikut ini.

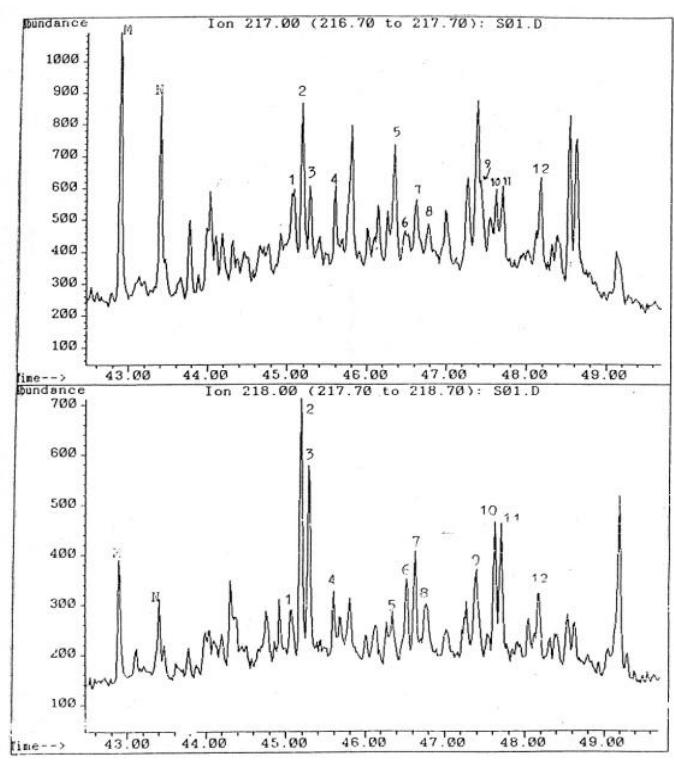

Gambar 1.a kromatogram massa pada m/z 217-218

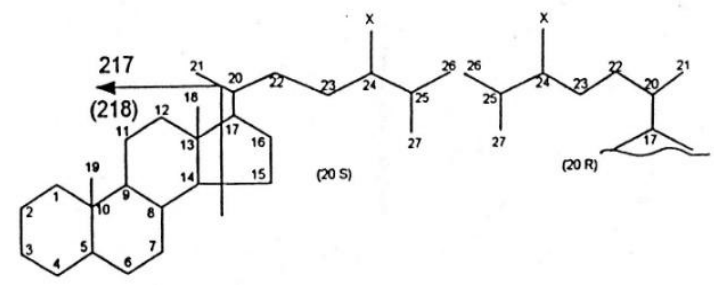

Gambar 1.b fragmentasi m/z 217 untuk golongan sterana

Kromatogram massa m/z 217 dan 218 sterana menunjukkan hasil sebagian yang ditabulasikan pada tabel 1 berikut ini.

Tabel 1 Identifikasi puncak sterana

\begin{tabular}{|c|c|c|}
\hline $\begin{array}{c}\text { No } \\
\text { Puncak }\end{array}$ & Nama senyawaan & $\begin{array}{l}\text { Jumlah } \\
\text { Karbon }\end{array}$ \\
\hline M & $5 \alpha(H), 14 \beta(H), 17 \alpha(H)$ sterana (20S) & 27 \\
\hline $\mathrm{N}$ & $5 \alpha(H), 14 \beta(H), 17 \alpha(H)$ sterana (2OR) & 27 \\
\hline 1 & $5 \alpha(H) .17 \alpha(H)$ sterana (20S) & 27 \\
\hline 2 & $5 \beta(H), 17 \beta(H)$ sterana $(20 R)$ & 27 \\
\hline 3 & $5 \beta(H), 17 \beta(H)$ sterana $(20 S)$ & 27 \\
\hline 4 & $5 \alpha(H), 17 \alpha(H)$ sterana $(20 R)$ & 27 \\
\hline 5 & 24-Metil-5 $\alpha(\mathrm{H}), 14 \alpha(\mathrm{H}), 17 \alpha(\mathrm{H})$ sterana (20S) & 28 \\
\hline 6 & 24-Metil-5 $\alpha(H), 14 \beta(H), 17 \beta(H)$ sterana (2OR) & 28 \\
\hline 7 & 24-Metil-5 $\alpha(\mathrm{H}), 14 \beta(\mathrm{H}), 17 \beta(\mathrm{H})$ sterana $(20 \mathrm{~S})$ & 28 \\
\hline 8 & 24-Metil-5 $\alpha(H), 14 \alpha(H), 17 \alpha(H)$ sterana (2OR) & 28 \\
\hline 9 & 24-Etil-5 $\alpha(H), 14 \alpha(H), 17 \alpha(H)$ sterana $(20 S)$ & 29 \\
\hline 10 & 24-Etil-5 $\alpha(H), 14 \beta(H), 17 \beta(H)$ sterana (2OR) & 29 \\
\hline 11 & 24-Etil-5 $\alpha(H), 14 \beta(H), 17 \beta(H)$ sterana $(20 S)$ & 29 \\
\hline 12 & $24-E t i l-5 \alpha(H), 14 \alpha(H), 17 \alpha(H)$ sterana (2OR) & 29 \\
\hline
\end{tabular}


Sedangkan hasil perhitungan $\mathrm{C}_{27}, \mathrm{C}_{28}$, dan $\mathrm{C}_{29}$ sterana pada keempat sampel minyak yang dianalisis menunjukkan kelimpahan yang relatif lebih tinggi pada $\mathrm{C}_{27}$ dibanding $\mathrm{C}_{28}$ dan $\mathrm{C}_{29}$ yang mengindikasikan bahwa material organik batuan sumber maupun lingkungan pengendapan minyak bumi dari sumur produksi Sumatra Tengah ini memiliki memiliki kemiripan satu sama lain. Jika fakta in ditinjau dengan metoda segitiga sterena sebagaimana yang dikemukakan oleh Huang dan Meinshein (1979) maka kelimpahan relatif yang terjadi pada $\mathrm{C}_{27}$ sterana pada keempat sumur produksi Sumatra Tengah ini termasuk tipe minyak bumi yang terdeposit pada lingkungan pengendapan yang hampir sama.

Kematangan sampel minyak bumi dapat ditentukan dengan perhitungan parameter sterana seperti ditunjukkan pada tabel 2 berikut ini.

Tabel 2 Data biomarker sterana minyak bumi sumur produksi sumatera tengah

\begin{tabular}{ccccc}
\hline & \multicolumn{4}{c}{ Sumur Minyak } \\
\cline { 2 - 5 } Parameter & $\mathrm{X}$ & $\mathrm{Y}$ & $\mathrm{Z}$ & $\mathrm{W}$ \\
\hline $\mathrm{C}_{27}$ sterana & 7.92 & 8.43 & 10.07 & 10.23 \\
$\mathrm{C}_{28}$ strerana & 4.04 & 3.82 & 4.84 & 4.81 \\
$\mathrm{C}_{29}$ sterana & 5.02 & 5.17 & 5.92 & 6.38 \\
$20 \mathrm{~S} /(\mathrm{S}+\mathrm{R})$ & 0.46 & 0.44 & 0.50 & 0.55 \\
$\beta \beta /(\beta \beta+\alpha \alpha)$ & 0.48 & 0.50 & 0.55 & 0.56 \\
\hline
\end{tabular}

Definisi, parameter dan perhitungan berdasarkan tabel 1

Perhitungan sterana baik untuk $20 \mathrm{~S} / 20(\mathrm{~S}+\mathrm{R})$ maupun $20 \beta \beta /(\beta \beta+\alpha \alpha)$ untuk masing-masing sampel dari sumur minyak ditunjukkan pada Tabel2 diatas. 20S/(S+R) pada penelitian ini berkisar $0.46-0.55$ dimana sampel $\mathrm{X}$ dan $\mathrm{Y}$ menunjukkan nilai yang lebih rendah, sedangkan nilai yang lebih tinggi terlihat pada sampel dari Sumur Z dan Sumur W. Jika mengacu kepada parameter kematangan (Seifer and Moldowan 1991; Peters dan Moldowan 1993) yang mencakup keseimbangan pada kisaran 0.50-0.55, maka keempat sampel minyak dari sumur produksi
Sumatra Tengah ini tergolong minyak yang matang. Perbedaan tipis angka kematangan masing-masing sampel sampel teranalisis berasal dari material organik yang tak berbada jauh dan telah mengalami proses pematangan yang hampir sama.

Selain parameter kematangan $20 \mathrm{~S} / 20(\mathrm{~S}+\mathrm{R})$, isomer rasio $20 \beta \beta /(\beta \beta+\alpha \alpha)$ juga dapat digunakan sebagai parameter cadangan (Peters dan Moldowan 1993). Bila melihat kisaran $20 \beta \beta /(\beta \beta+\alpha \alpha)$ pada sterana, maka hasil yang diperoleh juga menunjukkan bahwa keempat sampel minyak dari sumur produksi Sumatra Tengah ini termasuk minyak yang matang, dimana angka kematangan masingmasing sampel minyak menunjukkan dua kelompok yang lebih dekat korelasinya, yaitu sampel minyak $X$ yang lebih dekat terhadap sampel minyak $\mathrm{Y}$ dan sampel minyak $\mathrm{Z}$ yang lebih dekat korelasinya dengan sampel minyak W.

\section{Karakteristik Minyak Bumi Sumur Produksi Sumatra Tengah}

Keempat sampel teranalisis menunjukkan asal-usul dari batuan sumber yang komposisi utamanya Algal Kerogen (tipeI) yang deposit pada lingkungan danau atau payau sehingga minyak yang dihasilkan adalah tipe lacustrine ditujukkan dari rasio $\mathrm{C}_{26} \mathrm{~T} / \mathrm{C}_{25} \mathrm{~T}$ yang nilainya lebih dari 1.0 (Peters dan Woldowan 1993; ten Haven dan Schifelbein 1995). Indikasi tipe minyak bumi Lacustrine tersebut juga diperkuat dari rendahnya nilai rasio total sterana/total hopana yang nilainya jauh dibawah 1.0 dan rendahnya kelimpahan relatif $\mathrm{C}_{34}, \mathrm{C}_{35}$ homohopana (ten Haven dan Schifelbein 1995).

Meskipun kelimpahan relatif $\mathrm{C}_{27}$ sterana lebih tinggi dari $\mathrm{C}_{28}$ dan $\mathrm{C}_{29}$ sterana, tapi tidak ditemukannya $24-n$ propil sterana, sebagaimana yang ditunjukkan dari kromatogram GC-MS masing-masing sampel minyak dari Sumur $\mathrm{X}, \mathrm{Y}, \mathrm{Z}$ dan $\mathrm{W}$ ini bukan berasal dari lingkungan marin, dan juga bukan berasal dari lingkungan daratan atau tumbuhan tinggi, karena rendahnya kelimpahan relatif 
konstituen tumbuhan tingi seperti oleanana dan tidak terdeteksinya gammaserana. Demikianpula tingginya konsentrasi trisiklo terpana pada sampel minyak ini, semakin memperkuat data sebelumnya bahwa keempat sampel minyak bumi dari Sumur X,Y,Z dan W bukan karakter minyak darat. Ditemukannya biomarker botryoccocane, memastikan sampel minyak bumi dari keempat sumur produksi Sumatra Tengah ini termasuk minyak Lacustrine (tipe-I).

\section{Kematangan ThermalMinyak Bumi Antar Sumur Produksi}

Kematangan termal minyak bumi ditunjukkan dari parameter 20S/20(S+R) = 0.46 yang mengindikasikan sampel minyak keempat sumur yang dianalisis semuanya termasuk kategori minyak matang (Peters and Woldowan 1993).Meskipun masing-masing sampel minyak yang teranalisis menunjukkan tipikal yang sama, namun adanya perbedaan komposisi kimia antar sumur produksi Sumatra Tengah dapat digolongkan menjadi dua grup $\left(\mathrm{M}_{1}\right.$ dan $\left.\mathrm{M}_{2}\right)$ dimana minyak bumi dari Sumur W menunjukkan tingkat kematangan yang lebih dekat dengan minyak bumi dari sumur $\mathrm{Z}$ dibanding dari minyak bumi dari kedua Sumur produksi lainnya X,Y. Karakteristik minyak bumi dari empat sumur minyak dicekungan Sumatra Tengah dianalisis dari data biomarker seperti (1) distribusi n-alkana dan rasio $\mathrm{Pr} / \mathrm{Ph}$ (2) persentase kelimpahan relatif $\mathrm{C}_{27}-\mathrm{C}_{29}$ sterana.

Meskipun sampel minyak bumi dari keempat sumur produksi Sumatra Tengah tersebut menunjukkan Tipe minyak bumi dan lingkungan pengendapan yang sama, akan tetapi dari; (1) pola sebaran n-alkana, (2) rasio $\mathrm{Pr} / \mathrm{Ph}$, (3) $\mathrm{Pr} / \mathrm{n}-\mathrm{C}_{17}$ (4) $\mathrm{Pr} / \mathrm{n}-\mathrm{C}_{18}$ (5) persentase kelimpahan relatif $\mathrm{C}_{27}-\mathrm{C}_{29}$ sterana, yang dianalisis dengan analisis statistik multivarian. Hasil analisis statistik multivarian menunjukkan adanya dua tingkat kematangan yang sangat dekat, yaitu antara minyak bumi dari sumur produksi $\mathrm{W}$ dangan minyak bumi bumi dari Sumur Produksi Z. Sedangkan minyak bumi dari Sumur Produksi X menunjukkan tingkat kematangan yang lebih dekat dengan minyak bumi dari Sumur Y.

Pola sebaran biomarker pada masingmasing sampel teranalisis terlihat adanya kemiripan yang menunjukkan keempat sampel minyak bumi dari sumur produksi Sumatra Tengah ini memiliki kesamaan asal-usul material organik dan lingkungan pengendapansebagaimana yang ditunjukkan dari pola sebaran sterana. Meskipun pola sebaran biomarker pada masing-masing sampel teranalisis menunjukkan adanya kesamaan pola, tetapi sampel $\mathrm{X}$ menunjukkan kemiripan yang lebih dekat dengan sampel $\mathrm{Y}$, sedangkan sampel minyak $\mathrm{Z}$ lebih dekat kemiripannya dengan sampel minyak W. Fakta dari sebaran biomarker tersebut semakin memperkuat analisis sebelumnya, yaitu analisis sidik jari gas kromotografi yang menunjukkan bahwa sampel dari Sumur W yang baruditemukan tersebut memiliki tingkat kematangan yang sama dengan sampel minyak $\mathrm{Z}$ dari pada kedua sampel lainnya.

Dari data diatas diyakini bahwa minyak bumi dari keempat sumur produksi Sumatra Tengah ini memiliki asal-usul batuan sumber yang sama dengan dua reservoar berbeda, atau juga mungkin awalnya dari reservoar sama namum karena adanya patahan baru menyebabkan hidrokarbonnya beremigrasi ketempat yang berbeda. Perpindahan hidrokarbon kereservoar yang tidak terlalu jauh tersebut juga menyebabkan distribusi n-alkana, biomarker yang tidak berbeda terlalu jauh pula.Juga diyakini bahwa perbedaan antar sampel dari Sumur Minyak Sumatera Tengah ini menjadi ketegori grup $M_{1}$ dan grup $\mathrm{M}_{2}$, dimungkinkan dari perbedaan kelimpahan relatif-input material organik yang berasal dari tumbuhan darat atau tumbuhan tinggi sebagaimana yang ditunjukkan indek stearananya.Informasi yang ditunjukkan dari perolehan data pada penelitian ini selanjutnya dapat digunakan untuk eksplorasi lanjutan, misalnya untuk menunjukkan arah atau posisi eksplorasi lanjutan untuk mendapatkan minyak bumi yang termasuk $M_{1}$ atau kategori untuk 
grup $\mathrm{M}_{2}$ yang berada pada satu reservoar dengan minyak bumi dari Sumur W.

\section{Implikasi Geokimia}

Hasil analisis pada masing-masing sampel menunjukkan adanya hubungan tingkat kematangan yang positif antara sampel minyak $\mathrm{X}$ dan $\mathrm{Y}$, sedangkan sampel minyak $\mathrm{Z}$ memiliki tingkat kematangan yang lebih dekat dengan sampel dari Sumur minyak W tersebut mengimplikasikan bahwa sampel minyak dari sumur $\mathrm{X}$ berada satu layer dengan sampel minyak dari sumur $\mathrm{Y}$, sedangkan sampel minyak dari Sumur $\mathrm{Z}$ berada satu layer dengan sampel minyak dari sumur $\mathrm{W}$, yang bermakna bahwa minyak bumi dari sumur $\mathrm{W}$ tersebut berkomunikasi lebih baik dengan minyak bumi dari Sumur Minyak Z dari pada minyak bumi dari sumur-sumur minyak lainnya.

$$
\text { Implikasi tersebut menunjukkan }
$$

bahwa tindakan pengurasan lebih lanjut (Enhance Oil Recovery) terhadap minyak bumi dari Sumur Z dapat dilakukan dengan tehnik mendorong minyak bumi, yang dilakukan melalui sumur $\mathrm{W}$, karena minyak bumi dari sumur $\mathrm{W}$ tersebut berkomunikasi lebih baik dengan minyak bumi yang ada pada Sumur W.

\section{SIMPULAN}

Berdasarkan penelitian yang telah dilakukan dapat disimpulkan bahwadengan metode sidikjari, keempat sampel minyak bumi dari sumur produksi Sumatera Tengah ini dapat diklasifikasikan menjadi dua grup korelasi $\left(\mathrm{M}_{1}\right.$ dan $\left.\mathrm{M}_{2}\right)$, dimana sampel minyak dari sumur $\mathrm{W}$ menunjukkan tingkat kematangan yang lebih dekat dengan sampel minyak dari sumur Z, sedangkan sampel dari sumur minyak $\mathrm{X}$ memiliki tingkat kematangan yang lebih dekat dengan sampel dari sumur Y.

Pola biomarker keempat sampel minyak teranalisis, diyakini bahwa minyak bumi dari keempat sumur produksi Sumatera Tengah ini memiliki asal usul batuan sumber dan lingkungan pengendapan yang sama, namun karena adanya perbedaan lapisan reservoar menyebabkan hidrokarbonnya bermigrasi ketempat yang berbeda dan juga dimungkinkan dari perbedaan kelimpahan relatif-input material organik yang berasal dari tumbuhan darat atau tumbuhan tinggi, sebagaimana yang ditunjukkan dari indeks stereana. Fakta tersebut menyebabkan keempat sampel teranalisis terbagi menjadi dua kelompok dengan tingkat kematangan berbeda, dimana sampel $\mathrm{X}$ denan tingkat kematangan yang sama dengan sampel $\mathrm{Y}$, sedangkan sampel minyak dari sumur $\mathrm{W}$ lebih dekat tinkat kematangannya dengan sampel dari sumur Z.

Korelasi antar sampel minyak tersebut mengimplikasikan bahwa sampel minyak dari sumur $\mathrm{W}$ berada satu layer dengan sampel dari sumur Z, sedangkan sampel dari sumur minyak $X$ berada satu layer dengan sampel dari sumur minyak Y, artinya sampel dari sumur minyak $\mathrm{W}$ tersebut berkomunikasi lebih baik dengan sampel dari sumur $\mathrm{Z}$ dibandingkan sampel dari sumur-sumur minyak lain.

Fakta adanya perbedaan tingkat kematangan antar sampel tersebut, juga berimplikasi pada tehnik pengurasan lebih lanjut (enhance oil recovery), dimana untuk pengurasan lebih lanjut terhadap minyak bumi dari sumur $\mathrm{Z}$ dapat dilakukan dengan tehnik mendorong minyak bumi, yang dapat dilakukan dari sumur minyak $\mathrm{W}$, karena adanya komunikasi yang lebih baik.

\section{Daftar Pustaka}

Alexander R, Larcher AV, Kagi RI, Price PL. 1992.An oil source correlation study using age-specific plant-derived aromatic biomarker. Di dalam: Moldowan JM, Albrecht P, Philip RP. (ed). Biological Markers in Sediment and Petroleum. New Jersey (US): Prentice.

Dydik BM, Simoneit BRT, Brassell SC, Eglington G. 1978. Organic geochemical indicators of paleoenvironmental conditions of edimentation.Nature.272: 216 - 221.

Ten Haven HL, Schiefelbein C. 1995. The petroleum system of Indonesia. Proceedings 
of Indonesian Petroleum Association.24th Annual Convention.Jakarta.

Hunt JM. 1996. Petroleum Geochemistryand Geology. New York (US): Freeman.

Huang, J.M., Meinschein, W.G. 1979.Sterols as ecological indicators, Geochimica et Cosmochimca Act, Vol 43.

Katz BJ, Dawston WC. 1997. Petroleum system of Central Sumatra. Proceedings of the Indonesian Petroleum Association.16: 685695.

Kaufman RL, Ahmed AS, Elsinger RJ. 1990. Gas chomatography as a development and production tool for finger printing oils from individual reservoirs: Applications in the Gulf of Mexico. Di dalam: Schumacker D, Perkins BF. (ed). Proceedings of the 9th Annual Research Conference of the Society of Economic Paleontologists and Mineralogists. New Orleans.

Kaufman RL, Ahmed AS, Hempskins WBA. 1995. New technique for the analysis of commingled oils and its application calculation. Di dalam: Schumacker D,
Perkins BF. (ed). Proceedings of the Annual Reseach Conference of the Society of Economic Palaeontologists and Mineralogists Chevron Oil Field Research Company.

Koning. T. and Darmon, F. X, 1984, the geology of the beruk Northeast field, Central Sumatra, oil production from pre-Tertiary basement rocks,Proceeding of the Indonesia Petroleum Associastion, 13, 385 - 406.

Peters KE, Moldowan JM. 1993. The Biomarker Guide, Interpreting molecular Fossils in Petroleum and Ancient Sediments. New Jersey (US): Prentice.

SchiefelbeinJE, ZumbergeS.W,Brown. 1997 Petroleum System Of Far East. Proceedings of the Indonesian Petroleum Association.24th Annual Convention.Jakarta.

Seifert WK, Moldowan JM. 1981. Paleoreconstruction by biological markers. Geochimica et Cosmochimica Acta. 45: 783794.

Tissot BP, Welte DH. 1984. Petroleum Fomation and Occurrence. New York (US): SpringerVerlag. 